\title{
A 20 años de la reforma constitucional de 1994. Una experiencia de Convención Nacional Constituyente ${ }^{* *}$ At 20 years of the constitutional reform of 1994. An experience of a National Constitutional Convention
}

\section{Resumen}

* Doctor, profesor de Derecho Constitucional y de Derecho Público Provincialy Municipal, Universidad Nacional de Córdoba, Argentina. Académico de Número de la Academia Nacional de Derecho y Ciencias Sociales de Córdoba y Director de su Instituto de Federalismo. Académico Correspondiente de la Academia Nacional de Ciencias Morales y Politicas de Buenos Aires y de la Academia Internacional de Derecho Comparado de La Haya. Ex Vicepresidente de la Comisión de Redacción de la Convención Nacional Constituyente de 1994.

** Artículo recibido el 10 de septiembre de 2014 y aceptado para su publicación el $1^{\circ}$ de octubre de 2014.
El autor nos introduce, a partir de una perspectiva histórico - dogmática, a la reforma constitucional argentina de 1994. Para ello, el presente artículo se estructura en tres momentos o piezas que el autor disecciona con precisión y claridad: un período preconstituyente, destinado a diseñar el camino por el cual recorrería el esfuerzo reformista, la etapa constituyente sobre la cual se sitúa la mayor atención del autor y su análisis y la época postconstituyente caracterizada por la implementación de la reforma y la práctica institucional que devino de dicho cambio constitucional. ${ }^{1}$

\section{Palabras clave}

Reforma constitucional - Acuerdo de Olivos - Convención Constituyente.

\begin{abstract}
The author introduces us, from a historical-dogmatic perspective to the constitutional reform of 1994 in Argentina. Therefore this article is divided into three stages, or parts, which the author dissects with precision and clarity: one preconstituyente period aimed at design the way by which traverse the reform effort, the constitutional stage which gets most attention of the author and the postconstituyente period characterized by the implementation of the reform and institutional practice that became of that constitutional change.
\end{abstract}

\footnotetext{
Hemos desarrollado este análisis - que ahora actualizamos-en oportunidad de los 10 y 15 años de la reforma constitucional de 1994, en sendos artículos titulados "Valoración de la reforma constitucional de 1994 en su décimo aniversario" (Hernández, 2005) y "Balance de la reforma constitucional de 1994", (Hernández, 2009).
} 
Keywords

Constitutional reform - Agreement of Olivos - Constitutional Convention.

\section{Introducción}

Pensamos que para realizar un juicio de valor de una reforma constitucional se deben considerar los tres períodos del proceso constituyente: el "preconstituyente", de declaración de la necesidad de la reforma, a cargo del Congreso y que culmina con la elección popular de los convencionales; el "constituyente", con la Convención que ejercita el poder constituyente y sanciona las reformas, y el "postconstituyente", destinado a la reglamentación y cumplimiento de la reforma producida.

Asimismo para el período específicamente constituyente -al cual dedicaremos mayor atención-, analizaremos las siguientes cuestiones: la legitimidad de la reforma, sus ideas-fuerza, el diseño constitucional y la valoración de la misma.

Finalmente, abordaremos el período post-constituyente.

Por razones de brevedad nos limitaremos a una reflexión sintética y panorámica de tan importantes, complejas y trascendentes cuestiones.

\section{El proceso preconstituyente}

Este proceso fue signado por el denominado Acuerdo o Pacto de Olivos, que se concretara en pasos sucesivos, originados en una primera reunión, el 4 de noviembre de 1993, entre los líderes de los partidos políticos mayoritarios: Raúl Alfonsín por la Unión Cívica Radical y Carlos Saúl Menem por el Partido Justicialista, en dicha localidad de la Provincia de Buenos Aires ${ }^{2}$. Posteriormente se produjo la firma de un documento con fecha 14 de noviembre de 1993, que enumeró algunos de los puntos del acuerdo, en la residencia presidencial de $\mathrm{Olivos}^{3}$.

Ese acuerdo luego fue precisado y desarrollado mediante la intervención de una comisión de juristas de ambas fuerzas políticas ${ }^{4}$, para después ser suscrito formalmente

En la casa del ex Canciller durante la presidencia de Alfonsín, Dante Caputo. Cfr. Alfonsín (1996), pág. 311. El documento suscripto por los presidentes de ambos partidos con fecha 14 de noviembre de 1993, en la Residencia de Olivos, decía inicialmente: "En el día de la fecha se reunieron el Señor Presidente de la Nación y Presidente del Partido Justicialista, Dr. Carlos S. Menem, y el Señor Presidente de la Unión Cívica Radical, Dr. Raúl R. Alfonsín, con la finalidad de examinar temas relativos a la reforma de nuestra Constitución Nacional". Y más adelante se mencionaban los mismos, de manera muy sintética, en cuatro puntos: equilibrio de los poderes, independencia del Poder Judicial, rediseño del régimen federal e integración latinoamericana y continental. Cfr. Alfonsín (2004), pp. 206/7.

4 Que tuve el honor de integrar en nombre del Radicalismo de Córdoba junto al Dr. Jorge De la Rúa, sumándonos a otros miembros como los Dres. Alberto García Lema, Juan Carlos Maqueda, Ricardo Gil Lavedra y Enrique 
entre los partidos que ya lo habían aprobado por sus órganos respectivos, con fecha 13 de diciembre de 1993, en un acto celebrado en la Casa Rosada. ${ }^{5}$

En definitiva, el denominado Pacto o Acuerdo de Olivos, con sus contenidos definitivos, fue firmado en el acto previamente mencionado, en el que participaron, además de Carlos Menem y Raúl Alfonsín como presidentes de los partidos, Eduardo Menem, Carlos Ruckauf, Jorge Matzkin, Eduardo Bauzá, Carlos Corach y Alberto García Lema por el justicialismo y José Genoud, Raúl Galván, Antonio Berhongaray, Ricardo Gil Lavedra, Enrique Paixao, Arnoldo Klainer y el suscrito por el radicalismo ${ }^{6}$.

En base a ello fue sancionada la Ley Declaratoria de la Necesidad de la Reforma No 24.309, con los dos tercios de los votos totales de cada una de las Cámaras, con fecha 29 de diciembre de $1993^{7}$.

El Acuerdo o Pacto de Olivos previó un Núcleo de Coincidencias Básicas, que dieron base al art. $2^{\circ}$ de la ley citada, además de los otros temas habilitados para la reforma, incluidos en el art. $3^{\circ}$.

Ya una vez electos los convencionales constituyentes, una comisión de ellos ${ }^{8}$ trabajó en la redacción del proyecto de reforma constitucional relativo al Núcleo de Coincidencias Básicas, que luego fuera tratado por una comisión del mismo nombre de la Convención.

Considero ineludible y de toda justicia histórica recordar a Raúl Alfonsín, que, bajo mi punto de vista, coronó su obra institucional y política con la reforma constitucional de 1994, de la cual fue inspirador y artífice fundamental.

Ahora, cuando el juicio de la historia sobre su personalidad avanza, se destaca su desempeño en la Presidencia de la República y en la Convención Nacional Constituyente y su lucha inclaudicable por la libertad, los derechos humanos, la democracia social y los principios de la república federal. Pero por sobre todo, sus calidades personales de honradez, austeridad y hombría de bien y su compromiso con los valores de la república.

Tanto en su carácter de hombre político como de Estado, los representantes de distintos sectores partidarios, sociales, del periodismo y de la cultura han coincidido en reconocer su excepcional aporte al diálogo y a la búsqueda de los consensos, como camino esencial para profundizar la cultura política democrática en el país.

Y en ello debe encontrarse la justificación y fundamentación de su accionar en torno a la reforma constitucional y en particular, del Acuerdo o Pacto de Olivos.

Paixao, entre otros. Las reuniones se realizaron en el Salón Gris del Senado de la Nación y el documento se tituló "Puntos de acuerdos de las Comisiones de Juristas". Cfr. Alfonsín (2004), op. cit., pp. 208/9.

Luego se produjo la aprobación por parte de los órganos partidarios respectivos. El Radicalismo destinó para ello dos reuniones de su Convención Nacional, en las ciudades de La Pampa y de Vicente López, en la Provincia de Buenos Aires. En esta última tuve la responsabilidad de informar el proyecto constitucional del Radicalismo. Finalmente se firmó el Pacto o Acuerdo de Olivos, por los partidos políticos respectivos, en la fecha indicada. Cfr. Alfonsín (2004), op. cit., pp. 210/2.

6 Cfr. Alfonsín (2004), op. cit., pp. 210/2.

También participé en el debate legislativo en mi carácter de Vicepresidente del Bloque de Diputados Nacionales de la Unión Cívica Radical. Véase el libro de Hernández (1995).

8 Que también integré y que se reunió en una de las salas del Poder Judicial de la ciudad de Santa Fe. 
Sin lugar a dudas, este fue uno de los capítulos más complejos y decisivos de su vida. Y la prueba de ello es la especial atención que le dispensara a la cuestión en sus obras "Democracia y consenso"9 -especialmente- y "Memoria Política"10. Es que Alfonsín percibió el alto precio político que en su momento pagó -junto al radicalismo-, por la realización del Acuerdo, ya que no pocos desconocieron su gesto de trascendencia histórica y sostuvieron, en cambio, que con ello se perdía el carácter opositor al peronismo ${ }^{11}$.

Creemos que los detractores del Pacto privilegiaron una visión agonal de nuestra política y no comprendieron que era menester considerar la cuestión bajo el punto de vista arquitectónico.

9 Alfonsín (1996).

10 Alfonsín (1994), pp. 155 a 240.

11 En "Democracia y consenso", obr. cit., cuyo prólogo sostiene: "Este libro tiene varios propósitos, que quiero expresar claramente:

I. En primer lugar, procurar que se comprenda la urgencia de construir consensos que permitan resguardar los poderes democráticos, amenazados por la concentración del poder económico, la dispersión de los sectores políticos y el debilitamiento de las fuerzas de trabajo.

II. En segundo lugar, dar un testimonio que permita a la sociedad comprender mejor las circunstancias que explican el proceso de la reforma constitucional....

III. En tercer lugar, responder a las críticas que suscitó mi actitud en relación con el Pacto de Olivos. Para ello sostengo:

1) Que fue coherente con lo que he sostenido toda mi vida y, a la vez, expresiva de mi lucha política permanente en procura de la construcción de lo que llamo el Estado Legítimo.

2) Que el método para la construcción y consolidación del Estado Legítimo es el de la búsqueda de consensos que deben lograrse a través de una genuina actividad política, entendida como deliberación, discusión amplia y debate abierto.

3) Que en la actualidad, la construcción del estado legítimo requiere la participación activa y el compromiso de los sectores progresistas de la Nación.

4) Que es lícito establecer pactos circunscritos a temas específicos con sectores adversarios y aún hostiles, a fin de recuperar la democracia o resguardarla.

5) Que la reforma de la Constitución se hubiera realizado de todos modos, aunque mediara la oposición del radicalismo y de otras fuerzas políticas, y que eso habría implicado:

a. Pérdida de la legalidad y la consiguiente regresión a la época de las "negativas irreductibles", o grave desobediencia partidaria.

b. La sanción de una reforma retrógrada que hubiera significado: * la ausencia de modernización de institutos obsoletos y la permanencia de disfuncionalidades del sistema institucional. * El incremento del hiperpresidencialismo e incluso la posibilidad de una reelección indefinida. *El riesgo de constitucionalizar los principios del actual modelo económico. *Un "cheque en blanco" que podía producir insospechadas modificaciones de naturaleza desconocida.

6) Que la realización del plebiscito a que se había convocado vulneraba el espíritu de la Constitución y conspiraba contra la convivencia de los argentinos.

7) Que actué de acuerdo con la doctrina y la práctica de las mejores tradiciones de la Unión Cívica Radical.

8) Que la desorientación del radicalismo en todo el proceso previo al pacto había llegado a extremos peligrosos para su unidad y originado riesgos de feudalización.

9) Que la reforma recogió en gran parte las enmiendas del Consejo de Consolidación para la Democracia y mejoró y modernizó las instituciones de la Nación.

IV. En cuarto lugar, este libro tiene el propósito de cerrar una etapa de la discusión interna de la Unión Cívica Radical....

V. En quinto lugar, tiene el propósito de enaltecer la lucha de la Unión Cívica Radical a favor de los principios del Estado de Bienestar y propiciar en su seno una actitud firme y sistemática contra las postulaciones del neoconservadurismo, evitando cualquier forma de seducción que la saque de su cauce, abierto tras años de un esfuerzo que transcurrió sin cesar en procura de dotar a la democracia de contenido social" (Cfr. Obr. Cit., págs. 11/13). 
Desde esta perspectiva se advierte en plenitud la importancia de la obra constituyente en general y de Alfonsín en lo personal ${ }^{12}$. Pero además, ello significó un accionar coherente con las posiciones de su partido, que siempre se manifestó a favor de una reforma de la Constitución Nacional ${ }^{13}$. Y en particular, con su propia obra de gobierno, ya que a través del Consejo de Consolidación de la Democracia ${ }^{14}$ impulsó decididamente dicha tarea.

Por otra parte, es menester recordar la situación política en 1993. En aquel escenario se encontraba en tratamiento, en la Cámara de Diputados de la Nación, un proyecto de ley del Diputado Durañona y Vedia, que establecía como interpretación del art. 30 de la Constitución, que los dos tercios requeridos eran de los miembros presentes de cada Cámara. Y además, se proyectaba una Consulta popular sobre la reforma constitucional para posibilitar la reelección del Presidente Menem ${ }^{15}$. A eso hay que agregar que en algunas declaraciones del Bloque de Senadores Nacionales del Justicialismo se sostenía que la Constitución Nacional vigente era la sancionada en la reforma constitucional de 1949.

En dicha instancia, con un oficialismo decidido a avanzar en la reforma prácticamente a cualquier precio y con la magnitud de los problemas históricos observados en esta materia, resultó necesario concretar un acuerdo que modificase el rumbo de los acontecimientos políticos e institucionales, que se tornaban negativos e impredecibles para el país.

12 Insistimos en que el poder constituyente requiere fundamentalmente del ejercicio de la política constitucional, que se basa en grandes consensos políticos y sociales. Véase en tal sentido, los acuerdos políticos citados por Diego Valadés. (Cfr, Valadés y Carbonell, 2000, pp. 139 y ss.) como base de posteriores reformas constitucionales producidas en América Latina y que nosotros hemos resumido de la siguiente manera: "A) El acuerdo entre los partidos Conservador y Liberal de Colombia, ratificado mediante plebiscito en 1957 y también en dicho país, el proceso de negociación con sectores guerrilleros que posibilitara la reforma constitucional de 1991. B) Las modificaciones producidas en la Constitución de El Salvador, luego del acuerdo con el Frente Farabundo Martí, en 1991. C) El Pacto de Punto Fijo en Venezuela, en 1958, que posibilitó la reforma constitucional de 1961 (16). D) El Pacto de Olivos en Argentina, celebrado en 1993 entre los presidentes de las fuerzas políticas mayoritarias del Peronismo y del Radicalismo, Carlos Menem y Raúl Alfonsín, que sirviera de base a la Reforma Constitucional de 1994, para nosotros la más importante de la historia. E) El pacto que sirvió para la confirmación del frente político que se opuso al gobierno militar en Brasil y que sirvió para la reforma constitucional de 1988. F) Con relación a México, indica que se está viviendo un proceso inconcluso de negociación". Cfr. Hernández (2003), pp. 43 y sgts.

En relación a nuestro país, nos referimos a este tema en el propio seno de la Convención Nacional Constituyente -como más adelante se verá en el punto sobre la Legitimidad de la Reforma-, pero también debemos resaltar que es muy ilustrativo el análisis histórico realizado por Alfonsín sobre la extensión y magnitud de los desencuentros argentinos, que reclamaron y reclaman para su superación, verdaderas políticas de Estado en base a grandes acuerdos políticos y sociales. Cfr. Alfonsín (1996), op. cit. pp. 192 y sgts. Finalizamos este recuerdo de Alfonsín, rememorando su notable actuación en la Convención Constituyente, donde presidiera el Bloque de Convencionales de la Unión Cívica Radical en una tarea infatigable de alta calidad política, que fue reconocida por todos los miembros de la magna Asamblea.

13 Como también lo hicieron la mayoría de las fuerzas políticas del país. Cfr. Alfonsín (1996), op. cit. pp. 222/260. Además de los cultores de nuestra disciplina, donde se destacaron en dicha posición César Enrique Romero, Jorge Reinaldo Vanossi y Germán Bidart Campos.

14 Coordinado por Carlos Santiago Nino, integrado por representantes de diversas fuerzas políticas y que publicara dos dictámenes al respecto, que sirvieran de precedente para la Convención de Santa Fe y Paraná de 1994. Cfr. Alfonsín (1996), op. cit. pp. 137/188.

15 Cfr. Alfonsín (1996), op. cit. pp. 305 y sgts. 
Y el camino elegido fue el que correspondía: un acuerdo de dirigentes políticos, redactado por una comisión especializada, luego debatido y aprobado por las instancias institucionales respectivas de los partidos, para lograr el estricto cumplimiento del art. 30 de la Constitución Nacional, en la faz legislativa y preconstituyente, mediante la declaración de la necesidad de la reforma por el Congreso de la Nación. El proceso luego se completaría con la elección democrática de los Convencionales Nacionales Constituyentes, que con muy alto grado de consenso, sancionaran la reforma de 1994, que fuera la más legítima, amplia y profunda de la historia argentina.

No obstante ello, creemos que el controvertido juicio histórico y político sobre el Acuerdo de Olivos impidió un análisis correcto de su consecuencia institucional, que fue la reforma constitucional de 1994.

Esto se apreció por distintas razones: a) se puso énfasis sólo en el debate por el Pacto de Olivos, prescindiéndose de la reforma que fue su resultado; b) se ha intentado reducir la reforma prácticamente a la posibilidad de la reelección presidencial, y c) ha faltado un análisis más objetivo, profundo, sistemático e integral de la reforma ${ }^{16}$.

Hoy, a 20 años de la reforma, advertimos que el panorama antes descrito se ha ido modificando.

\section{La legitimidad de la reforma}

El problema de la legitimidad de la Constitución -dice Linares Quintana ${ }^{17}$ - es de naturaleza esencialmente política, y debe resolverse remontándose hasta la naturaleza del acto constituyente. Este autor coincide con Sánchez Viamonte en que para la legitimidad constitucional, el acto constituyente debe ser la expresión genuina de la voluntad del pueblo, surgida de una libre determinación mayoritaria.

Nosotros analizamos detenidamente la legalidad y legitimidad de la reforma constitucional de 1994 en el propio seno de la Convención Nacional Constituyente ${ }^{18}$.

Allí recordamos los debates producidos con motivo de las reformas constitucionales, comenzando con la de 1860 . Desde la necesidad de sostener que existió ejercicio de poder constituyente originario y abierto ${ }^{19}$-iniciado en 1810 y terminando en 1860 con la incorporación de la provincia de Buenos Aires a la Confederación-, ya que

16 Esto no ha sido nuevo en nuestra historia. Recuérdese al respecto el tenor de las opiniones emitidas por personalidades de la talla de Alberdi y Sarmiento, fruto de las tremendas pasiones desatadas en los debates producidos con motivo de las Convenciones Constituyentes de 1853 y 1860.

17 Linares Quintana (1953), p. 139.

18 Ver nuestra intervención del día 8 de junio de 1994 en la obra "Reforma constitucional de 1994. Labor del convencional constituyente Antonio María Hernández (h.)", Imprenta del Congreso de la Nación, Buenos Aires, 1995, ps. 49/57. Para un análisis completo de la teoría del poder constituyente, véase HeRNÁNDEZ (2012).

19 Como lo hicieron Carlos Sánchez Viamonte y Germán Bidart Campos. 
de lo contrario se podría impugnar la constitucionalidad de la reforma, porque una cláusula del texto de 1853 prohibía que se efectuara dentro de los 10 primeros años.

Lo propio ocurrió posteriormente con la cuestión de los dos tercios de votos -presentes o totales- de las cámaras. Y aunque la reforma de 1898 no mereció objeción, sabemos que no tenía vigencia la república democrática, pues no se ejercitaba adecuadamente la soberanía popular. Ya en el siglo XX, el momento de máximo enfrentamiento político fue con motivo de la reforma de 1949, que tuvo el signo partidario del oficialismo y fue impugnada en su legalidad y legitimidad por la oposición y gran parte de la doctrina, porque faltaron los dos tercios de votos de la totalidad de sus miembros en la Cámara de Diputados. También hubo objeciones a la reforma de 1957, efectuada con la proscripción del justicialismo. Y por si faltara algo, tuvimos además un ejercicio autocrático de poder constituyente, con la reforma de facto de 1972.

Hemos sostenido que este debate permanente sobre el "status constitucional" ha sido la prueba de nuestra falta de cultura política y jurídica. Por ello es conveniente recordar a Joaquín V. González, en su "Juicio del Siglo" en 1910, cuando destacó que la ley de la discordia interna había protagonizado la vida política de los argentinos. ${ }^{20}$

Y ello explica nuestra dificultad para alcanzar acuerdos durante nuestra historia que nos permitiesen reformar la Ley Suprema, mientras nos hemos caracterizado por las violaciones permanentes de ella.

Recordamos también en la Convención el pensamiento alberdiano sobre la constitución como una transacción política fundamental y, en efecto, que la reforma debía ser el fruto del consenso de las fuerzas políticas y sociales.

En este sentido, la ley No 24.309 -de declaración de la necesidad de la última reforma-, tuvo las mayorías exigidas constitucionalmente por el art. 30 de la Ley Suprema, o sea, más de dos tercios de la totalidad de los miembros de cada una de las cámaras; y los convencionales fueron electos en comicios absolutamente limpios, con vigencia del Estado de Derecho y de las libertades públicas. Mas allá de las objeciones efectuadas a la ley -para nosotros superadas con la adopción del Reglamento por parte de la Convención ${ }^{21}$-, hoy parece ya acallado el debate al respecto.

La Convención de Santa Fe y Paraná tuvo 305 convencionales -la suma del número de los miembros del Congreso: 257 diputados y 48 senadores-, que representaron a 19 bloques políticos ${ }^{22}$.

Fue la Convención más numerosa de la historia argentina, que realizó su tarea en sólo 90 días, en un marco ejemplar de pluralismo democrático -como lo sostuvieron los

20 Y por eso, siguiendo a Tagore, sostuvo que no nos comprendíamos porque no nos amamos y no nos amábamos porque no nos comprendíamos.

21 Para un análisis circunstanciado del histórico debate sobre el Reglamento de la Convención, que comprendió la cuestión de la legalidad y legitimidad de la reforma, ver el interesante y agudo libro de Quiroga Lavié (1996).

22 Aunque dicha cifra se elevó a 20, cuando al final de las sesiones de la Convención se otorgó el reconocimiento, como bloque unipersonal, al integrado por Iván Cullen. 
distintos partidos políticos-, y que produjo la más importante reforma constitucional, tanto en la parte dogmática como en la parte orgánica. Existió muy alto grado de acuerdo para la sanción de 61 normas constitucionales: 20 nuevas, 24 reformadas y 17 disposiciones transitorias.

En el amplio contexto de nuestra historia institucional, consideramos que ésta es la reforma con mayor legalidad y legitimidad, y que además clausuró dolorosas etapas de frustraciones y desencuentros, que incidieron gravemente en la vida nacional. No por casualidad la reforma fue efectuada en el proceso democrático más extenso que hemos tenido a partir de 1930 y en tal sentido, creemos que fue el punto culminante de dicha experiencia política y jurídica, pues expresó el momento más importante de ejercicio de política arquitectónica en nuestro tiempo.

Téngase presente que la política constitucional es la quintaesencia de la política arquitectónica, pues debe basarse en amplios consensos sobre las grandes ideas, valores, objetivos y sueños de una sociedad en su más trascendente proyecto político nacional, que es la Ley Suprema.

La Constitución Nacional que nos rige es la de 1853, con las reformas de 1860, 1866, 1898,1957 y 1994, tal como fue jurada por los convencionales y autoridades federales el 24 de agosto de 1999, en el histórico Palacio de San José, que perteneciera al ilustre general Justo José de Urquiza, el prócer máximo de la organización nacional.

\section{Las ideas - fuerza de la reforma}

Consideramos pertinente recordar aquí lo que señalamos sobre este particular en los fundamentos de nuestro proyecto integral de Reforma de la Constitución Nacional, presentado en la Convención Constituyente ${ }^{23}$ :

"El contenido del proyecto que propiciamos está inspirado por seis ideas fuerza: a) la atenuación del presidencialismo; b) la modernización y fortalecimiento del Congreso; c) la garantía de la independencia del Poder Judicial; d) el fortalecimiento del federalismo y las autonomías municipales; e) el otorgamiento de un nuevo status a la Ciudad de Buenos Aires; $y f$ ) el reconocimiento de nuevos derechos y garantias constitucionales".

En cuanto a la atenuación del presidencialismo, destacamos la creación de la figura de un jefe de gabinete de ministros, lo que implica la posibilidad de reforzamiento del

23 Véase nuestro Proyecto de Reforma Constitucional, que abarcó todos los puntos de la reforma según lo dispuesto por la ley declaratoria $\mathrm{N}^{0}$ 24.309, presentado en la Convención Nacional Constituyente de 1994, bajo el $N^{0} 72$, que obra en el Diario de Sesiones de la Convención y en los libros Hernández (1995), pp. 26 y sgts. y Hernández (1997), en el apéndice. Por otra parte, adviértase la coincidencia con lo expuesto sobre el particular por el Convencional Alberto García Lema en los debates de la Convención, -también integrante de la Comisión de Redacción-, lo que se encuentra mencionado en el trabajo precedente a éste. 
control del Congreso frente al Ejecutivo. En efecto, el jefe de gabinete será responsable ante el Congreso que podrá removerlo a través de un voto de censura. La introducción de la figura del jefe de gabinete y su responsabilidad ante el Congreso no altera la esencia del régimen presidencialista, pero introduce un correctivo que atempera la excesiva concentración de poder en el Ejecutivo presidencial.

La reducción del mandato presidencial a cuatro ańos, con la posibilidad de una sola reelección, apunta en la misma dirección señalada, al tiempo que permite una cierta flexibilización de las tensiones que se desarrollan en el entramado político por la excesiva duración del mandato y su corte abrupto, sin posibilidad de continuidad. La solución que propiciamos está abonada por una larga serie de antecedentes en el derecho comparado, en el derecho público provincial argentino y por la opinión mayoritaria de la doctrina constitucional. La posibilidad de la reelección, con un período de cuatro años, no implica lesión alguna al sistema republicano porque es el pueblo el depositario de la soberanía y quien, en definitiva, va a resolver la continuidad o no de una gestión presidencial.

Para reforzar la participación ciudadana en este sentido, se introduce la elección directa de la fórmula presidencial. El sistema de doble vuelta proyectado apunta a reforzar la legitimidad de los gobernantes, garantizando a quien gobierna el respaldo de una amplia mayoría de la ciudadanía. El sistema propuesto permite, al mismo tiempo, evitar el desgaste de una nueva elección cuando los guarismos electorales anticipan ya un grado de legitimidad suficiente.

El abuso de los antes excepcionales decretos de necesidad y urgencia que han caracterizado la gestión presidencial hace indispensable la introducción de límites y controles a esta atribución que la Corte Suprema reconoció al Presidente en el caso "Peralta". En este sentido propiciamos el establecimiento de límites en cuanto a la materia regulable, estableciendo que los decretos de necesidad y urgencia no podrán normar temas como régimen de partidos políticos y sistema electoral, ni tampoco legislación penal y tributaria. Se asegura, asimismo, el control del Congreso sobre el ejercicio de esta facultad que se confiere como excepcional, frente a situaciones de emergencia que hagan imposible seguir los procesos legislativos ordinarios. En la misma línea de limitación del poder presidencial, se inscribe la regulación de la delegación legislativa que, conforme al proyecto, sólo procederá por tiempo determinado y sobre materia expresa, conservando el Congreso el control de lo actuado por el Poder Ejecutivo. Además queda claro que siempre se tratará de lo que la doctrina y la jurisprudencia de la Corte Suprema caracterizan como delegación impropia. Como sostuvo Meynaud, la eficacia es la regla de oro del gobierno moderno; las modificaciones que hemos comentado apuntan en esa dirección, compatibilizando eficacia y control.

El propósito de moderación de las facultades presidenciales se manifiesta también en otros aspectos del proyecto. Mencionemos algunos de estos puntos. La necesidad del acuerdo del Senado para la designación de funcionarios de los organismos de control y del Banco Central es uno de estos mecanismos, con lo cual el Senado argentino se 
acerca al modelo de su par norteamericano. Los controles externos a que será sometido el sector público nacional a través de la Auditoría General, a la que se otorga rango constitucional, apuntan en la misma dirección. En este caso se refuerza la capacidad de la Auditoría al hacerla depender del Congreso y encargar su dirección a la oposición parlamentaria. La creación de la figura del Defensor del Pueblo se inscribe en la misma línea, al igual que la garantía de independencia del Ministerio Público que tiende a afirmar el estilo republicano, mediante el fortalecimiento de los poderes de control del Congreso y del Poder Judicial.

La segunda idea fuerza es la modernización y fortalecimiento del Congreso. Un análisis detenido de la política argentina, en la última década, muestra el aumento de las atribuciones del Presidente en detrimento del Congreso. A esto se suma un creciente desprestigio del Congreso frente a la opinión pública, fenómeno que se repite en otras partes del mundo. El fortalecimiento del Congreso y la revalorización de sus funciones en el Estado moderno es uno de los imperativos de hora. En efecto, se trata de revitalizar la función representativa, de redimensionar -al mismo tiempo- la función del Congreso como ámbito de debate y diseño de políticas públicas y finalmente, de rescatar y dinamizar las funciones de control que son propias de un Congreso republicano.

Estos son los ejes que impulsan las reformas en materia de integración y funcionamiento del Congreso. En primer lugar, se proyecta la elección directa de los senadores, con lo que se garantiza una mayor participación de los ciudadanos y se refuerza el carácter representativo democrático del cuerpo. Al mismo tiempo se crea la figura del Senador por la minoría, ampliando la representatividad política del cuerpo y garantizando de modo más eficaz un pluralismo enriquecedor del debate.

En cuanto al proceso de sanción de las leyes, la dinámica moderna exige una agilización de los trámites, por lo cual se propone la reducción a tres de las lecturas previstas para cada proyecto. Además, se incorporan en el proyecto instituciones como el trámite de urgencia y la aprobación en particular de proyectos de ley en comisión. Asimismo se propone la creación de comisiones de enlace entre las cámaras, lo que facilitará el desenvolvimiento de ambas ramas del Congreso y la pronta y coordinada consideración de las iniciativas. Estos mecanismos contribuirán a mejorar el papel del Congreso en los procesos decisorios vinculados a las políticas públicas.

Como dijimos, una de las funciones esenciales del Congreso es la relacionada con el control del Ejecutivo. Cuando ese control es débil o llega tarde, el equilibrio de los poderes se desdibuja y la República corre el riesgo de una concentración excesiva del poder e incluso de la utilización discrecional y arbitraria del mismo. Para evitar estos peligros, el proyecto refuerza la función de control a través de numerosos mecanismos, entre los que cabe mencionar, por ejemplo, el control del Congreso sobre los decretos de necesidad y urgencia y los actos del Ejecutivo derivados de delegación del Congreso, así como sobre la promulgación parcial de leyes por el Ejecutivo. El proyecto redefine, en la misma línea de acción, las facultades del Congreso en cuanto a los pedidos de informes y a la interpelación y regula la formación de comisiones de investigación. 
Finalmente, la incorporación del Jefe de Gabinete va acompañada de la posibilidad de control congresional a través del voto de censura.

La tercera idea fuerza que impulsa este proyecto es la de vigorizar la independencia del Poder Judicial. Asistimos a una profunda crisis de confianza en la institución judicial, de lo que dan muestras numerosos estudios de opinión. Es necesario revertir ese proceso de desprestigio que puede minar uno de los baluartes del sistema democrático. En este sentido se proponen mecanismos de despolitización de los procedimientos de nombramiento y remoción de los magistrados que garantizarán no sólo idonei$\mathrm{dad}$, sino independencia de los jueces frente a las posibles presiones políticas. A este objetivo apuntan la creación del Consejo de la Magistratura y el establecimiento del Jurado de Enjuiciamiento de Magistrados. La Argentina se pondrá así a la altura de las legislaciones más modernas en la materia. Los jurados de enjuiciamiento, a su vez, permiten evitar los desvíos a los que ha conducido la remoción por juicio político, mecanismo que se reserva -en el proyecto- para los magistrados del máximo tribunal.

La designación de miembros de la Corte Suprema con el voto de los dos tercios de los miembros presentes en el Senado para brindar acuerdo, en audiencias públicas, garantizará que lleguen al más alto tribunal de la Nación, los hombres de mayor autoridad jurídica y moral, atento a la responsabilidad que le cabe a la Corte como intérprete final e irrevocable de la Constitución. La revigorización del Poder Judicial se completa con la constitucionalización del Ministerio Público como órgano extrapoder, a la que ya hemos hecho referencia.

La cuarta idea que informa este proyecto es la de fortalecer el régimen federal y la autonomía municipal. El desproporcionado y desequilibrado desarrollo de la Argentina es una realidad palmaria que no requiere mayor comentario. El presente y el futuro de la Nación requieren de un federalismo moderno de concertación y no de confrontación, de cooperación interjurisdiccional y regional y no de competencia y desequilibrio desgastante. Uno de los aspectos a contemplar para dar nueva forma al federalismo argentino, es el de las relaciones económico-financieras de la Nación y las provincias para evitar que, desde el gobierno central, se avasallen sistemáticamente las autonomías provinciales. La institución de la coparticipación federal de impuestos no puede basarse en la imposición del gobierno central a las provincias, sino en el acuerdo y consenso entre las jurisdicciones involucradas. Como decía Alberdi, "sin finanzas, sin rentas, no hay gobierno". En este mismo orden, se reconoce a las provincias su capacidad de decisión autónoma sobre los recursos naturales, cuyo dominio es innegable.

Siempre con miras a un federalismo moderno, el proyecto contempla la posibilidad de las provincias de celebrar acuerdos internacionales sin afectar las facultades propias del gobierno central. Una gestión de negocios moderna y exitosa, en el marco de un mundo cada vez más integrado e interdependiente, requiere de estas herramientas, sin las cuales los gobiernos provinciales quedan sujetos al humor del funcionario de turno del gobierno federal. Este mecanismo permitirá, asimismo, el fortalecimiento de las economías regionales. 
La regionalización es un instrumento apto para el desarrollo económico y social de importantes sectores de nuestro territorio. En tal sentido, el proyecto prevé la posibilidad de crear regiones en un marco de coordinación y consenso, evitando la imposición, desde escritorios de tecnócratas, de estructuras carentes de sustento real. La regulación de la competencia provincial en los establecimientos de utilidad nacional también está contemplada en el proyecto. Se saldan así reiteradas discusiones doctrinarias y conflictos políticos que no siempre tuvieron uniforme resolución en los estrados de la Justicia.

Por último, propiciamos el reconocimiento constitucional de la autonomía municipal, como base misma de la organización democrática. La Constitución Nacional se pondrá así a tono con los desarrollos del derecho público provincial argentino que, en una posición de avanzada, ha reconocido ya el principio de la autonomía municipal.

La quinta idea fuerza que impulsa este proyecto es la vinculada con la Ciudad de Buenos Aires, a la que se la dota de autonomía para designar a sus autoridades. La elección popular del intendente del distrito es un reclamo unánime de la ciudadanía. El proyecto prevé mecanismos transitorios para el gobierno de la ciudad hasta la constitución definitiva de sus autoridades, la que será el resultado de las deliberaciones de una convención convocada al efecto y electa directamente por los vecinos de la ciudad. La Ciudad de Buenos Aires tendrá así la posibilidad de darse sus instituciones, como lo han hecho ya muchos municipios del país.

El reconocimiento de nuevos derechos y garantías para los habitantes de la Nación, además del otorgamiento de rango constitucional a algunos tratados internacionales de derechos humanos, constituye la sexta idea fuerza que ha guiado la elaboración del presente proyecto. Lugar destacado en este capítulo merece el reconocimiento de los mecanismos de democracia semidirecta: la iniciativa popular y la consulta no vinculante. El proyecto propone también la constitucionalización del amparo y el hábeas corpus, que son las máximas garantías de los derechos de las personas. Además, se contempla los derechos a un medio ambiente sano y los derechos de los usuarios y consumidores, el respeto del derecho a organizar partidos políticos democráticos y las garantías esenciales del derecho del sufragio, sin cristalizar fórmulas que se trasforman, con el tiempo, en obstáculos insalvables para el desarrollo político. Se otorga rango constitucional a los tratados internacionales sobre derechos humanos. Se incorpora expresamente el derecho de las comunidades indígenas a una integración que respete su idiosincrasia y su cultura. Se prevé, también, la creación de un Consejo Económico Social con carácter consultivo, "institución propia de una moderna concepción de la democracia social y participativa."

A dicha enumeración de ideas - fuerza debemos agregarle una séptima, que para nosotros es el afianzamiento de los procesos de integración tanto nacional como supranacionales. En efecto, la reforma persiguió la alta finalidad de consolidar la integración en sus diversas fases, como una respuesta eficaz a los desafíos del mundo globalizado en que vivimos. 


\section{El diseño constitucional y la práctica institucional posterior}

Corresponde que aquí analicemos si el diseño del constituyente fue adecuado a las ideas fuerza que guiaron la reforma. En tal sentido, efectuaremos nuestra valoración en relación a cada una de las ideas antes mencionadas.

Con respecto a la primera, la atenuación del presidencialismo, es la que ha suscitado mayores controversias, con diversas críticas ante la continuidad del fenómeno del "hiper - presidencialismo" 24 .

Mereciendo el tema un análisis más detallado de instituciones, que no podemos ahora realizar por razones de brevedad, creemos que en general los cambios introducidos en el texto fueron acertados, aunque en la vigencia sociológica no se cumplieran.

En efecto, para corregir nuestro "hiper - presidencialismo", basado en el modelo alberdiano -de presidencialismo más fuerte que el norteamericano por la influencia de la Constitución chilena de 1833-, que además se acentuó por las prácticas políticas, las emergencias, el debilitamiento del Congreso, el inadecuado ejercicio del control de constitucionalidad en especial de la Corte Suprema y los golpes de Estado, el constituyente de 1994 adoptó las siguientes principales modificaciones:

1. Privación de una de sus jefaturas al Presidente como fue la de la Capital Federal, en cuya virtud a lo largo de la historia pudo designar por sí mismo al Intendente de la Ciudad de Buenos Aires.

2. Fortalecimiento del Congreso mediante distintas reformas, que más adelante analizaremos y que persiguen un mejor equilibrio de los poderes dentro de nuestro sistema republicano. En tal aspecto, ahora mencionamos la ampliación del período ordinario de sesiones, las mayores atribuciones para la declaración de la intervención federal, la creación de la figura del Jefe de Gabinete de Ministros que debe rendir mensualmente informe ante cada una de las Cámaras y que puede ser removido por un voto de censura y la creación de órganos de control que tienen relación funcional con el mismo.

3. Reducción de las atribuciones del Presidente en la designación de los miembros del Poder Judicial mediante la creación del Consejo de la Magistratura y la sesión pública del Senado establecida para el acuerdo a los Ministros de la Corte Suprema.

24 Para nosotros, este fenómeno se caracteriza por la concentración del poder en el Presidente, más allá de las competencias fijadas por la Constitución, en desmedro de la división y equilibrio de los poderes y de los principios de la democracia constitucional. Debemos a Carlos Santiago Nino el más agudo y profundo estudio de esta grave patología institucional, que produce inconmensurables efectos negativos para el sistema político y jurídico y para una sociedad abierta porque impide la vigencia de una democracia deliberativa, en su obra Nino (1992), donde expuso el tema con visión interdisciplinaria. También se detuvo en el análisis del carácter corporativo de nuestro hiperpresidencialismo, que en nuestros días se manifiesta con particular fuerza. Véase además, HeRNÁndEZ (2012). 
4. Fortalecimiento de las autonomías provinciales y municipales, para reducir las atribuciones del Gobierno Federal y afirmar el control vertical del poder ${ }^{25}$, como otro objetivo del federalismo.

5. Jerarquización constitucional de órganos de control como la Auditoría General de la Nación, el Defensor del Pueblo y el Ministerio Público, con la finalidad de profundizar el control propio del sistema republicano.

6. Reducción del mandato del Presidente a 4 años, con posibilidad de una reelección inmediata y elección directa, como había sido reclamado desde hace ańos por la mayoría de los partidos políticos, la doctrina y los precedentes constitucionales de 1949, 1957 y 1972, además de ser la tendencia predominante en el derecho comparado, incluso latinoamericano.

7. Incorporación al texto constitucional de los decretos de necesidad y urgencia y la legislación delegada, como institutos de emergencia convalidados por la jurisprudencia de la Corte Suprema de Justicia desde los casos "Peralta" (1990) y "Delfino" (1927) y con la indiscutible finalidad de limitar las atribuciones del Poder Ejecutivo en el ejercicio de los mismos, como emerge de los arts. $99^{\circ}$ inc. 3 y 76 y de los debates de la Convención Constituyente.

8. Creación del Jefe de Gabinete de Ministros, como institución de cierta hibridez por su origen parlamentario en un sistema presidencialista ${ }^{26}$ y con la finalidad de morigerar el hiper - presidencialismo y servir para asegurar la gobernabilidad en situaciones de crisis políticas, como también se observa en la letra y debates de la Convención.

Reiterando nuestro acuerdo con el diseño normativo realizado por la Convención, consideramos que por la falta de cumplimiento de la Constitución y permanente violación de la ley, no se ha verificado en el orden de la realidad una atenuación del hiper - presidencialismo como el constituyente lo legisló. Porque si bien en algunos aspectos funcionaron como limitaciones parciales las indicadas en los puntos 1, 3, 4 y 5, no se ha podido verificar en cambio que los otros puntos hayan logrado su propósito.

En particular, consideramos criticable la declinación por el Congreso de sus atribuciones, especialmente por la sanción de las leyes de emergencia económica como la 25.561, con amplísimas delegaciones legislativas, prorrogada hasta nuestros días;

25 Como lo expresaron Madison y Hamilton en los "Federalist papers" y Loewenstein desde la doctrina constitucional y la teoría del federalismo.

26 Esta ha sido la tendencia consagrada en las 14 reformas constitucionales producidas sobre un total de 18 países de América Latina, según lo analiza especialmente VaLADÉs (2008), con prólogo de mi autoría, y VALADÉS (2007). En dichos libros, el distinguido constitucionalista mexicano reabre con agudeza el debate que habían producido politólogos como Linz, Valenzuela, Sartori y Nohlen, en torno al presidencialismo y parlamentarismo en América Latina, inclinándose por la renovación del primero mediante la incorporación de instituciones del segundo, a los fines de morigerar la concentración del poder presidencial y racionalizar su ejercicio. Que es lo que estableció el constitucionalismo latinoamericano -incluido nuestro país-, más allá de los problemas observados posteriormente en las prácticas institucionales, que muestran la distancia entre la norma y la realidad. 
el uso excesivo de decretos de necesidad y urgencia y de legislación delegada por la Presidencia, sin controles del Congreso; la inconstitucional reglamentación efectuada por la Ley 26.122; la concesión de los llamados superpoderes en la administración financiera y presupuestaria al Jefe de Gabinete de Ministros; la práctica institucional de este último órgano, que en modo alguno ha atenuado los poderes presidenciales ni servido hasta ahora en una situación de crisis, como la de fines de 2001 durante la Presidencia de De la Rúa.

Consideramos que de las normas redactadas, merece especial mención por su brevedad la del art. 76 sobre delegación legislativa, que ha originado dificultades de interpretación y una práctica abusiva por parte del propio Congreso y de la Presidencia.

Esta cuestión debiera ser superada por una adecuada reglamentación del Congreso y un correcto y celoso ejercicio de sus competencias, además de una firme jurisprudencia de los tribunales, como se hizo por la Corte Suprema en el célebre caso "Provincia de San Luis”, donde nuestro más alto tribunal efectuó una acertada interpretación sobre el alcance de la emergencia y el uso de los decretos de necesidad y urgencia y de la delegación legislativa ${ }^{27}$.

Pese a que el diseño constitucional de 1994 significó una modificación del fuerte presidencialismo del texto originario de 1853, hoy en Argentina se gobierna por muy pocas personas ${ }^{28}$ y por medio de decretos ${ }^{29}$, sin el debido control por parte del Congreso ${ }^{30} \mathrm{ni}$ en general del Poder Judicial y de la Corte Suprema de Justicia en particular, aunque deben destacarse algunos fallos que sí lo hicieron ${ }^{31}$.

27 Y más recientemente, en el caso "Camaronera Patagónica SA c. Ministerio de Economía y otros s/amparo", sobre principio de legalidad en materia tributaria y limitación de las delegaciones, fallado por la Corte en 2014.

28 La titular del Poder Ejecutivo y unos pocos colaboradores.

29 Delegados o de necesidad y urgencia. Y a veces ni siquiera ello, como ocurriera con la Resolución 125 sobre las retenciones agrarias, que originara un gran conflicto político y que finalmente fuera rechazada por el voto del Senado de la Nación al intentarse su convalidación mediante un proyecto de ley enviado por el Poder Ejecutivo. No obstante ello, el Poder Ejecutivo, mediante Decreto 1076 del año 2008, ha seguido reivindicando su atribución de fijar las retenciones, en base a lo legislado inconstitucionalmente en los arts. 755 y concordantes del Código Aduanero, que fuera dictado por un gobierno de facto y que estableciera una delegación de facultades tributarias en el Presidente.

30 Una excepción de ello fue el rechazo del proyecto de Ley del Poder Ejecutivo que pretendía la convalidación de la Resolución 125 sobre retenciones -como notoria expresión de hiperpresidencialismo pues se trataba de materia tributaria-, producido en el Senado de la Nación en julio del año 2008. Véase nuestro artículo HERNÁNDEZ (2008), pp. 40 y sgts..

31 Piénsese en tal sentido, que no ha existido un adecuado control de constitucionalidad en materia de emergencia económica, dado que en varios casos y en especial en "Bustos" y "Massa" se convalidó la misma en relación al "corralito", véase nuestro artículo HERnÁNDEZ (2007), pp. 25 y sgts. Tampoco la Corte Suprema intervino en relación a las retenciones agrarias, la estatización de las AFJP, la reglamentación de los decretos de necesidad y urgencia por la Ley $\mathrm{N}^{\circ} 26.122$, la Ley del Consejo de la Magistratura $\mathrm{N}^{\circ} 26.080$ o las candidaturas testimoniales, pese a las graves objeciones y planteamientos judiciales presentados en dichas cuestiones. En cambio, deben señalarse positivamente la declaración de inconstitucionalidad de la Ley $\mathrm{N}^{\mathrm{0}} 26.855$ del Consejo de la Magistratura, en sus arts. 2, 4, 18 y 30, según Fallo de la Corte de 2013 en el caso "Rizzo" y en el caso "Camaronera Patagónica SA", de 2014, con respecto a las violaciones del principio de legalidad en materia tributaria y al exceso de las delegaciones. Igualmente deben destacarse los fallos "Smith" y "Provincia de San Luis", fallados por nuestro más alto tribunal de la Nación en 2001 y 2003, respectivamente, en relación al "corralito" y la emergencia económica. Cfr. HeRnÁndez (2003). 
En relación específica a los decretos de necesidad y urgencia, aunque se ha reglamentado el art. 99 inc. 3 de la Ley Suprema que estableció la Comisión Bicameral Permanente para el control de dichos decretos, por medio de la Ley No 26.122 en 2007, la mayoría que ejerce el partido del gobierno en la misma ha significado en la práctica que actúe simplemente para convalidar los decretos dictados, que han superado holgadamente el número de proyectos de leyes enviados por el Poder Ejecutivo al Congreso. ${ }^{32}$

Estas ostensibles violaciones del sistema republicano y de nuestra democracia constitucional, son consecuencia de una notoria falta de cultura política, jurídica y democrática. ${ }^{33}$

En cuanto a la idea fuerza de modernizar y fortalecer el Congreso, también estimamos correcta la decisión del constituyente a través de estos principales cambios institucionales:

1. Ampliación del período ordinario de sesiones.

2. Elección directa de los Senadores, con reducción de su mandato a 6 años y aumento de sus atribuciones en materias federales.

3. Nuevo procedimiento para la sanción de las leyes.

4. Creación de nuevos órganos de control como la Auditoría General de la Nación y la Defensoría del Pueblo, con relación funcional con el Congreso.

32 Según editorial del 11 de septiembre de 2007 del diario 'La Nación' de Buenos Aires, el Presidente Kirchner suscribió durante su mandato 249 Decretos de Necesidad y Urgencia frente al envío de sólo 174 proyectos de ley remitidos al Congreso. Asimismo, con acertado criterio constitucional, se sostenía en dicho documento en relación a la Ley 26.122: "Es que la ley que reguló el trámite y los alcances de la intervención del Congreso frente al dictado de DNU -sólo sancionada 12 años después de aprobada la reforma constitucional- no estableció término alguno para que las cámaras se expidieran al respecto ni, menos aún, la caducidad de los DNU no ratificados dentro de un plazo determinado. Peor aún, establece esa ley que para rechazar uno de estos decretos se deben expedir en el mismo sentido ambas cámaras, de manera que si una cámara lo rechaza y la otra lo aprueba, el decreto seguirá vigente. Esto determina que, aun con mayoría en una sola de las cámaras, el Poder Ejecutivo puede en la práctica emitir disposiciones de carácter legislativo sin limitación alguna. Por esta vía se llegó a una deformación del sistema republicano, por la que en la Argentina actual es más fácil conseguir la aprobación parlamentaria de un decreto que obtenerla para un proyecto de ley. De ese modo, en vez de desalentarse, se estimula la emisión de esta clase de normas de carácter muy excepcional". Además de dicha reglamentación alejada del espíritu de la Constitución, insistimos en que al número de decretos de necesidad y urgencia hay que sumar otra enorme cantidad de decretos delegados -en razón de la ley de emergencia económica citada-, lo que ratifica nuestra afirmación acerca del gobierno por decreto en nuestro país, como muestra inexcusable de la decadencia de nuestro estado de derecho.

33 Véase nuestro libro "Las emergencias y el orden constitucional", en sus dos ediciones ya citadas, donde estudiamos detenidamente cómo se fue produciendo en nuestra historia institucional dicha decadencia del estado de derecho, que afectara el sistema republicano y la vigencia de los derechos individuales, mediante la utilización de emergencias permanentes. En particular, ello significó el avance del Ejecutivo junto a una declinación del Congreso, sin los suficientes controles de constitucionalidad por parte del Poder Judicial. Quien más estudió el fenómeno de la "anomia" fue Nino (1992). Este autor calificaba a la anomia como "boba" (por los daños que producía) y "antidemocrática" (porque se desconocía la ley que es fruto en principio de una deliberación y sanción de carácter democráticos). Por nuestra parte, cuando ejercimos la Presidencia de la Asociación Argentina de Derecho Constitucional, realizamos un trabajo interdisciplinario sobre cultura de la constitución y la legalidad, que se tituló "Encuesta de cultura constitucional. Argentina, una sociedad anómica", de Hernández, Zovatto y Mora (2005), y que es parte de un proyecto regional latinoamericano, pues ya se han producido encuestas similares en México y Bolivia. Allí se explica nuestro subdesarrollo cultural, político y democrático en relación a esta cuestión, sintetizada en el propio título del libro. 
5. Necesidad de reglamentación por el Congreso de los decretos de necesidad y urgencia y la legislación delegada, para la actuación de la Comisión Bicameral Permanente y el control de los institutos por dicho cuerpo legislativo.

6. Asignación de mayores atribuciones en la declaración de las intervenciones federales.

7. Reconocimiento de su competencia para remover por voto de censura al jefe del Gabinete de Ministros, quien deberá además presentarse mensualmente ante cada una de las Cámaras para informar.

8. Reconocimiento de competencia para otorgar rango constitucional a tratados de derechos humanos.

Estas importantísimas reformas, a las cuales intenté añadir mayores competencias al Senado para otorgar acuerdos para las designaciones del Presidente, no han tenido tampoco la vigencia que nuestro sistema político requiere, de conformidad a los principios republicanos.

Nos afecta especialmente señalar la declinación del Congreso en el ejercicio de su trascendente rol tanto de legislación como de control, tal como lo ejemplificamos con los aspectos mencionados en la anterior idea fuerza y los que mencionaremos más adelante.

Respecto a la idea fuerza de garantizar la independencia del Poder Judicial, fue también implementada para nosotros acertadamente mediante estas instituciones:

1. Creación del Consejo de la Magistratura.

2. Creación del Jurado de Enjuiciamiento de Magistrados.

3. Creación del Ministerio Público.

Estas tres instituciones están funcionando, pero es evidente que de manera progresiva se ha ido afectando la independencia del Poder Judicial, y por tanto, se ha violado el sistema republicano de la Constitución. Ello se debe a lo acontecido con las dos primeras instituciones, que en un primer momento fueron reglamentadas a través de las Leyes No 24.937 y 24.939, para posteriormente ser modificadas por la Ley No 26.080. Sobre esta última, la Academia Nacional de Derecho y Ciencias Sociales de Córdoba dictaminó lo siguiente en sus conclusiones:

"Que la nueva ley 26.080, recientemente sancionada por el Congreso de la Nación, no se adecua a los arts. 114 y 115 de la Constitución Nacional, que establecen que el equilibrio entre los sectores en el Consejo de la Magistratura y en el Jurado de Enjuiciamiento, es el principio fundamental para la integración de ambas instituciones. Que la inconstitucionalidad de la nueva ley resulta evidente puesto que se ha otorgado a la representación de los órganos politicos la mayoría de los cargos tanto en el Consejo como en el Jurado de Enjuiciamiento. Que esta ley inconstitucional significa no sólo una grave lesión al principio 
de la independencia del Poder Judicial, que es esencial para el funcionamiento de nuestro sistema republicano y del Estado Constitucional y Democrático de Derecho, sino además una violación a los principios que surgen de la Constitución Nacional...."34.

Pero tal como lo referimos anteriormente, se produjo un intento más grave por parte del oficialismo gobernante para avanzar en el control del Consejo de la Magistratura, mediante la sanción de la Ley No 26.855, que fue declarada inconstitucional en varios de sus artículos por la Corte Suprema de Justicia de la Nación, en el caso "Rizzo", en 2013.

Esa propuesta integró junto a otras que seguidamente comentamos, lo que se denominó como la "democratización de la justicia" 35 . Por nuestra parte, sostuvimos que democratizar no era "partidizar" 36 .

Por eso también consideramos como inconstitucional la Ley No 26.854 de 2013, que limita las medidas cautelares, porque ello lesiona gravemente los derechos y garantías consagrados en la Constitución Nacional y en Tratados Internacionales de Derechos Humanos. Es inconcebible una vigencia de esos derechos y una justicia oportuna, sin dichas medidas cautelares. Piénsese qué hubiese ocurrido con el "corralito" sin las mismas. $\mathrm{O}$ con la situación de tantos sectores populares que sufren la arbitrariedad especialmente del Estado, comenzando por los jubilados. Para nosotros, lo verdaderamente democrático y progresista es lo que se dispuso en la reforma de 1994, en torno a derechos y garantías, en los arts. 43 y correlativos. Y eso es lo que se debe respetar.

Asimismo objetamos otra Ley sancionada al respecto, la No 26.853 de creación de las Cámaras Nacionales de Casación en lo Contencioso administrativo, en Trabajo y Seguridad social y en lo Civil y Comercial, porque entre otras cosas, servirán para demorar aún más las causas y para centralizar aún más en Buenos Aires las funciones judiciales, lo que afecta el federalismo.

34 Dictamen de la Academia Nacional de Derecho y Ciencias Sociales de Córdoba, aprobado en la Sesión Ordinaria del 14 de marzo de 2006 y que llevó la firma del Presidente de la Academia, Dr. Olsen Ghirardi y del Secretario Dr. Ernesto Rey Caro.

35 Propósito que compartimos, pero que debe implementarse a través de otras propuestas distintas, como vgr:: instaurar el juicio por jurados, modificar los códigos procesales para una justicia más rápida y eficaz, garantizar la tutela judicial efectiva y la independencia del Poder Judicial. En igual sentido, sí consideramos conducentes para la democratización de la justicia, los otros proyectos enunciados por el Gobierno como los de ingreso por concurso a la administración de justicia, la publicación de las declaraciones juradas de magistrados y funcionarios y los de la tramitación de las causas. Volviendo sobre el juicio por jurados, recordamos que oportunamente presentamos un Proyecto de Ley al respecto, cuando ejercimos una Banca en la Cámara de Diputados de la Nación. Véase la obra de Hernández (1995).

36 Véase HeRnÁndEZ (2013), donde explicamos que el objetivo de la reforma constitucional fue corregir los excesos de la "politización de la justicia", mediante la creación del Consejo de la Magistratura, con una integración equilibrada de diversos sectores, para asegurar la independencia del Poder Judicial. 
En relación al fortalecimiento del federalismo y las autonomías municipales, afirmamos nuestro especial acuerdo con las decisiones del Poder constituyente que tuvimos el honor de integrar. En tal sentido, señalamos sintéticamente estas modificaciones ${ }^{37}$ :

-En los aspectos institucionales y politicos:

1. Los cuatro órdenes de gobierno de la federación argentina, o sea el Gobierno Federal, las provincias, la Ciudad Autónoma de Buenos Aires y los municipios autónomos.

2. La distribución de competencias, cuyo principio general se ha mantenido pero con mayores competencias reconocidas a las provincias.

3. El Senado y su rol federal, con el objetivo de acentuar el rol federal del mismo mediante la elección directa de sus miembros, la incorporación del tercer Senador y la asignación de mayores competencias.

4. La intervención federal, cuya declaración corresponde esencialmente al Congreso, modificando la práctica anterior que mostró al Presidente actuando por Decreto en las $2 / 3$ partes de los casos observados.

5. Los partidos políticos y el federalismo, porque consideramos que los mismos deben dar cumplimiento al ideario y prácticas federales en su funcionamiento.

-En los aspectos financieros:

1. La coparticipación impositiva, con el objetivo de sancionar una ley - convenio como instrumento del federalismo de concertación, para solucionar los graves problemas de nuestro federalismo fiscal.

2. El organismo fiscal federal, como institución fundamental para asegurar el buen funcionamiento de las relaciones fiscales interjurisdiccionales y del sistema anteriormente mencionado.

3. Pautas federales del presupuesto nacional, para la inversión con criterio "federal" de los fondos públicos por parte del Gobierno Federal.

-En los aspectos económicos y sociales:

1. El Banco Federal, para modificar el actual Banco Central, más propio de estados unitarios.

2. Las regiones para el desarrollo económico y social, como nueva alternativa para fortalecer nuestro federalismo y revertir el inadecuado ordenamiento territorial que se observa.

37 Para un análisis exhaustivo de las reformas en cuanto a la descentralización del poder, y en particular el federalismo y la consagración de la autonomía municipal, véase nuestra obra citada (HERNÁNDEZ, 1997). 
3. Las provincias y los convenios internacionales, como una de las bases esenciales para modernizar nuestro derecho público, en el marco de un regionalismo abierto y un mundo globalizado.

4. Las provincias y el dominio originario de sus recursos naturales, como otra de las más trascendentes decisiones de la Convención en reconocimiento de las autonomías provinciales ${ }^{38}$.

5. Organismos de seguridad social y otras facultades concurrentes, ratificando los principios de división de competencias y de las autonomías locales.

6. Principios federales en educación, ciencia y cultura, con criterios y objetivos similares a los del punto anterior.

Asimismo, se ha consagrado el principio de la autonomía municipal en sus diversos aspectos institucional, politico, administrativo, económico y financiero, como una obligación que las provincias deben asegurar.

Pensamos que el más somero análisis comparativo con otras federaciones existentes en el mundo, nos exhibe con un muy adecuado diseño de federalismo, con apreciable descentralización del poder y reconocimiento de las autonomías locales.

Pero también aquí se observa una notoria distancia entre la norma y la realidad, pues existe un evidente incumplimiento del proyecto federal de la Constitución que se advierte con un simple repaso de los puntos no respetados. Hemos analizado esta cuestión en distintos artículos, a los que remitimos en razón de brevedad ${ }^{39}$, donde hacemos referencia a los problemas de desigualdad, injusticia, inequidad y desintegración, ocasionados, entre otras causas, por la extrema centralización del país.

En cuanto al reconocimiento de la autonomía municipal, podemos decir con orgullo que Argentina, luego de la reforma, se encuentra en la posición más avanzada en el derecho comparado mundial. Pero también aquí debemos distinguir la norma de la realidad, pues a pesar de los notorios avances producidos, todavía es permanente la lucha que debe librarse por el cumplimiento efectivo del principio y su respeto por parte de los otros órdenes gubernamentales. Piénsese solamente en las tres provincias (Buenos Aires, Santa Fe y Mendoza) que todavía no han adecuado sus respectivas Constituciones a la Federal para la sanción de Cartas Orgánicas Municipales, entre otros casos, como el sufrido por la Municipalidad de San Luis -avasallada por el Gobierno Provincial-, finalmente resuelto por la propia Corte Suprema de Justicia de la Nación en el caso "Ponce, Carlos Alberto" ${ }^{40}$.

Respecto al otorgamiento de un nuevo status a la Ciudad de Buenos Aires, estimamos que éste fue otro de los grandes aciertos del constituyente, para afirmar la descentralización

\section{Véase HERNÁNDEZ (2014).}

HeRNÁNDEZ (2004), pp. 263/297; HERNÁNDEZ (2008), pp. 11 y sgts., y recientemente, HeRNÁNDEZ (2014).

Que hemos comentado en nuestro artículo titulado "La Corte Suprema como garante de la autonomía municipal", Hernández (2005), pp. 146 y sgts., donde destacamos especialmente la trascendencia de este fallo, en la valiosa línea de otros antecedentes como "Rivademar". 
del poder y reconocer una autonomía institucional especial a la ciudad, que en nuestro concepto es la de una Ciudad-Estado como las de Berlín, Bremen y Hamburgo en el federalismo alemán.

Así como el diseño constitucional fue correcto, en la reglamentación efectuada por el Congreso, a través de las leyes 24.588 y 24.620 , no se respetó la normativa suprema del art. 129 y es necesario efectuar las modificaciones necesarias para el cumplimiento estricto de ésta, que supone entre otras cuestiones que la Ciudad Autónoma debe tener su propia justicia -en todos los fueros- y su propia policía y registros públicos ${ }^{41}$.

Sobre el reconocimiento de nuevos derechos y garantías constitucionales y el otorgamiento de jerarquía suprema a algunos tratados internacionales de derechos humanos, creemos que también existe amplio consenso en cuanto al diseño constitucional elegido por la Convención Constituyente.

Aquí la finalidad fue profundizar la filosofía humanista y personalista de la Constitución, que hace de los derechos humanos su más importante objeto. Y la reforma ha aumentado notablemente el reconocimiento de derechos y garantías, que ahora tienen su fuente interna, tanto en la parte dogmática como orgánica de la Ley Suprema y su fuente externa, mediante el otorgamiento de rango constitucional a once instrumentos internacionales de derechos humanos en el art. 75 inc. 22 y la posibilidad de que otros tratados alcancen igual jerarquía, como nueva atribución del Congreso de la Nación, como ya ocurrió en dos $\operatorname{casos}^{42}$.

También se observa el notable avance obtenido en la materia a la luz del derecho comparado, así como las graves dificultades observadas para la efectiva vigencia de los derechos humanos en nuestro país, como consecuencia de la violación permanente de la ley y el uso inconstitucional de los institutos de emergencia. Ejemplo paradigmático de esta lamentable realidad fue el "corralito" -entre otros efectos derivados de la emergencia económica que todavía padecemos-y la violación de los derechos económicos y sociales, como lo indican los altísimos índices de pobreza, marginación y exclusión social que actualmente padecemos.

Finalmente, en relación a la séptima idea fuerza, el afianzamiento de los procesos de integración tanto nacional como supranacionales, igualmente consideramos que fue acertada la reforma producida.

Se consagró no sólo la posibilidad de la creación de regiones por parte de las provincias (art. 124), sino también la celebración de tratados de integración que deleguen competencias y jurisdicción a organizaciones supraestatales por parte del Gobierno Federal (art. 75 inc. 24). Esta ha sido la manera adecuada de promover la integración en sus distintos órdenes, como uno de los caminos sobre los que existen menores

41 Para un estudio detenido del tema, véase nuestra obra citada Hernández (1997), Cap. IV y el artículo "El federalismo a diez años de la reforma constitucional de 1994", HERNÁNDEZ (2004), también de nuestra autoría en la obra citada HERNÁNDEZ (2004).

42 No nos podemos detener en el análisis de estas cuestiones, a las cuales prestara tanta atención el recordado maestro Germán Bidart Campos. 
disidencias, para enfrentar las complejas y variadas situaciones que presenta el mundo globalizado, competitivo e interdependiente de nuestros días ${ }^{43}$. También, en este aspecto de la realidad se pueden apreciar avances y retrocesos, que por razones de brevedad no podemos considerar.

\section{La modernización constitucional}

Para nosotros, el primer resultado de esta obra constituyente ha sido la modernización constitucional, lo que se confirma de manera rotunda desde una visión de derecho comparado.

En este sentido, creemos que en la historia de nuestra disciplina hubo tres grandes períodos consecutivos y superadores: a) el constitucionalismo liberal o clásico, b) el constitucionalismo social y c) el derecho constitucional de la internacionalización de los derechos humanos.

Desde esta perspectiva, nuestro texto originario de 1853 se inscribió en el primer período, mientras que el tránsito hacia el constitucionalismo social se produjo con las reformas constitucionales de 1949 y de 1957, siendo profundizado en la última reforma de 1994. Pero además, ésta nos introdujo en la última etapa, correspondiente a la internacionalización de los derechos humanos, en un notable avance cualitativo.

Este tercer período es el resultado de la formidable lucha de las Naciones Unidas por cumplir el más grande objetivo de su Carta, sancionada luego de la Segunda Guerra Mundial, donde se abatiera el fenómeno oprobioso del totalitarismo nazi.

Los sucesivos Tratados de Derechos Humanos fueron introduciendo profundos cambios en nuestra disciplina y en el derecho en general y hoy constituyen una de las realidades del mundo globalizado que vivimos.

En ese marco, las Constituciones Nacionales fueron reconociendo una mayor vinculación entre el derecho interno y el internacional público y se fueron admitiendo los procesos de integración, con creación de organismos supranacionales y sistemas jurídicos regionales y mundiales destinados a la protección de los derechos humanos, además de la aparición de un derecho comunitario, con su máxima expresión en la Unión Europea.

Y ahora nuestro país cuenta con las normas jurídicas supremas para avanzar en tan promisorios procesos, encontrándose en una posición de vanguardia dentro de los sistemas constitucionales comparados.

Pero como la reforma tuvo entre sus fuentes a nuestro constitucionalismo provincial, conforme a nuestra forma federal de Estado, no debemos olvidar que en este aspecto fueron precursoras las reformas constitucionales de Neuquén (1957), San Juan (1986)

43 Véase nuestro libro HERNÁNDEZ (2000). 
y Córdoba (1987), que en disposiciones complementarias hicieron referencia a algunos Tratados de Derechos Humanos.

Esta modernización se advierte además en todos los aspectos vinculados a la organización del poder, o sea a la parte orgánica de la Constitución, y en particular a su descentralización.

Ya hemos destacado lo acontecido en cuanto al federalismo, la autonomía municipal y la Ciudad Autónoma de Buenos Aires, que nos coloca igualmente en una situación de particular relevancia desde el punto de vista normativo, con una lectura comparatista.

Y en cuanto a los otros cambios introducidos en el Gobierno Federal, también se aprecia la modernización, con influencias que han provenido tanto del constitucionalismo comparado como desde nuestro constitucionalismo provincial, que también se anticipó en la introducción de nuevas instituciones.

En síntesis, la reforma efectuada -con su legitimidad y grandes aciertos y algunas imperfecciones ${ }^{44}$ - produjo una modernización del texto constitucional, tanto en su parte dogmática como orgánica, sentando las bases para un desarrollo progresivo de nuestro derecho rumbo al siglo XXI.

\section{El periodo post-constituyente y el incumplimiento de la constitución nacional}

El derecho constitucional opera en los ámbitos de la libertad, el poder y la política. Y esto se aprecia especialmente cuando se trata del poder constituyente y de la política constitucional, que requieren del ejercicio de una política arquitectónica más que de una agonal.

Y con la "tosca materia” -como decían los clásicos- de que está hecha la política -y la nuestra en particular-, -por lo que afirmaba Joaquín V. González-, fue muy difícil alcanzar aquélla clase de política basada en grandes consensos.

Los altísimos grados de acuerdos que indicaron las distintas votaciones de los artículos yel final del texto completo de la reforma y su posterior juramento por todos los Convencionales demuestran que en 1994 ella se alcanzó.

Pero en la etapa "post-constituyente", destinada a la reglamentación y cumplimiento de la reforma, que también exige esa política, nosotros apreciamos que la misma dejó de practicarse.

Y la política agonal a la que volvimos -que esencialmente ha primado en la historia argentina- nos dio como resultado un deficiente y parcial cumplimiento de la Ley Suprema.

44 Ya que no hay obra humana perfecta y hacen falta dioses y no hombres para hacer las leyes, como decía Rousseau. 
No podemos dejar de mencionar la grave responsabilidad del Congreso en el incumplimiento de la sanción de las leyes reglamentarias de la Constitución. En efecto, se trata aproximadamente de 25 Leyes necesarias para la plena vigencia de la reforma, de las que se han sancionado menos de la mitad, y en algunos casos, de manera inconstitucional. ${ }^{45}$

Respecto de las normas no sancionadas, entre otras mencionamos las modificatorias del amparo y Auditoría General de la Nación, las regulatorias de la posesión y propiedad comunitarias de los indígenas, del crecimiento armónico de la Nación y que tiendan a superar el desigual desarrollo relativo de provincias y regiones, las que reglamentan las acciones positivas, y las modificatorias y derogatorias de la legislación anticonstitucional y centralista que todavía está vigente ${ }^{46}$. Por otra parte, es inexplicable que el Congreso no haya designado al Defensor del Pueblo de la Nación, a pesar que han transcurrido más de 5 años del alejamiento del anterior titular.

Obsérvese además la defección de nuestros Poderes Ejecutivos y Legislativos Federales y Provinciales, que no han avanzado en la sanción de la Ley Convenio de Coparticipación Impositiva, pese a que el plazo fijado fuera el 31 de diciembre de 1996.

Esta crítica también alcanza a otros operadores de la Constitución, como la Corte Suprema de Justicia, que en el caso "Fayt" (1999) declarara la nulidad del artículo 99 inc. 4 y la Disposición Transitoria Undécima, desconociendo la reforma y los principios de la teoría constitucional ${ }^{47}$.

Pero no se trata solamente del Gobierno Federal, ya que es bien conocida la violación flagrante de la Ley Suprema en que están incurriendo tres provincias (Buenos Aires, Mendoza y Santa Fe), que no han producido sus respectivas reformas constitucionales para dar cumplimiento al art. 123 sobre la autonomía municipal.

Pero sería un error pensar que sólo se incumple la Reforma de 1994. Mas allá de que la reforma es la Constitución en sí misma, en nuestro país lo que se viola permanentemente es la Ley en general, empezando por la Constitución, que es la Ley primera y Suprema.

Y ello ocurre con casi toda la Constitución, pues no podemos llegar a otra conclusión luego de una somera observación de la vigencia efectiva de los derechos humanos y el funcionamiento de nuestro sistema republicano y federal. Es decir que las violaciones empiezan desde el preámbulo y el art. 1.

Hace tiempo que venimos insistiendo en esta trascendente cuestión y al respecto hemos desarrollado, en una de nuestras obras ${ }^{48}$, la tesis de que las emergencias han sido el argumento utilizado permanentemente para incumplir la Constitución, afectar el sistema republicano y lesionar los derechos humanos a lo largo de nuestra historia.

45 Como en los casos del Consejo de la Magistratura -recién señalados No 26.080 y 26.855-, de la de Decretos de Necesidad y Urgencia No 26.122 y sobre la autonomía de la Ciudad Autónoma de Buenos Aires No 24.588 y 24.620, que restringieron la misma. Véase Hernández (2009), Cap.V.

46 Véase Hernández (2014), específicamente Propuesta 14, donde nos detenemos en esta cuestión.

47 Véase nuestro libro HeRnÁNDEZ (2012).

48 Hernández (2002) y $2^{\mathrm{a}}$ ed. ampliada, Universidad Nacional Autónoma de México y Rubinzal-Culzoni Editores, México, 2003. 
Asimismo hemos publicado una Encuesta sobre Cultura de la Constitución, que demuestra -desde la sociología con el posterior análisis interdisciplinario desde lo político y lo jurídico- la magnitud y profundidad del desconocimiento de la Ley Suprema en nuestra sociedad. ${ }^{49}$

Ello nos impele a continuar abogando por la necesidad de volver a la educación popular y democrática como el mejor camino para superar el subdesarrollo jurídico y político que padecemos ${ }^{50}$.

Insistimos en que debemos poner el énfasis en el cumplimiento de la ley y de la Constitución en especial, para desarrollar nuestro proyecto nacional, que está allí claramente contemplado.

Finalmente, a 20 años de la reforma constitucional de 1994, ya es tiempo de ejecutar con fidelidad sus mandatos, así como los demás de la Ley Suprema de la Nación. ${ }^{51}$

VIII. Referencias bibliográficas.

ALFONSÍN, Raúl (1996): Democracia y Consenso, Corregidor y Tiempo de Ideas, Buenos Aires, 1996.

ALFONSÍN, Raúl (2004): Memoria Política. Transición a la democracia y derechos humanos, Fondo de Cultura Económica, Buenos Aires, 2004.

ASOCIACIÓN ARGENTINA DE DERECHO CONSTITUCIONAL (2005): A diez años de la reforma constitucional, Editorial Advocatus, Córdoba.

HERnÁnDEZ, Antonio María (2012): Derecho Constitucional, Tomo 1, La Ley, Buenos Aires.

HERNÁNDEZ, Antonio María (1995): Labor parlamentaria del Diputado Dr. Antonio M. Hernández, 1991-1994, 2 Tomos, Imprenta del H. Congreso de la Nación, Buenos Aires.

HERNÁNDEZ, Antonio María (1995): Reforma constitucional de 1994. Labor del Convencional Constituyente Antonio María Hernández, Imprenta del H. Congreso de la Nación, Buenos Aires.

HERNÁNDEZ, ANTONio María (1997): Federalismo, autonomía municipaly ciudad de Buenos Aires en la reforma constitucional de 1994, Depalma, Buenos Aires.

49 Véase Hernández, Zovatto y Mora y Araujo (2005).

50 Entre las medidas que hemos propuesto al respecto, es menester poner el énfasis en la educación cívica y democrática, asentada en los valores y principios de la Constitución Nacional, como lo dispone la Ley $\mathrm{N}^{\circ} 25.863$-cuya sanción lográramos en 2003 cuando ejercíamos la Presidencia de la Asociación Argentina de Derecho Constitucional-, que también se incumple. Dicha norma fija el $1^{\circ}$ de Mayo como Día de la Constitución Nacional y obliga a la enseñanza de la misma en todos los niveles educativos.

51 Véase Hernández (2012). En esta obra analizamos, especialmente desde lo constitucional, los 100 años transcurridos entre 1910 y 2010, señalando nuestros graves problemas de cultura constitucional y de legalidad y proponiendo las soluciones respectivas. 
HERNÁNDEZ, Antonio María (2000): Integración y globalización: rol de las regiones, provincias y municipios, Depalma, Buenos Aires.

HERNÁNDEZ, Antonio María (2001 y 2012): El caso Fayt y sus implicancias constitucionales, $1^{a}$ Ed., Academia Nacional de Derecho y Ciencias Sociales de Córdoba, Córdoba, y 2a Ed., Abeledo Perrot, Buenos Aires, 2012.

HERNÁNDEZ, Antonio María (2003): "Perspectivas de los sistemas políticos y constitucionales en América Latina”, en: Debates de Actualidad, Asociación Argentina de Derecho Constitucional, Año XVIII, No 190, abril-junio de 2003, págs. 43 y sgts.

HERNÁNDEZ, Antonio María (2003): Las emergencias y el orden constitucional, 2a Ed., UNAM y Rubinzal Culzoni, México.

HERNÁNDEZ, Antonio María (2004): "El federalismo a diez años de la reforma constitucional de 1994”, pp. 263 - 297, en: BIDART CAMPOS, Germán y GIL DOMÍNGUEZ, Andrés, A una década de la reforma constitucional 1994-2004, Ediar, Buenos Aires, 2004.

HERNÁNDEZ, Antonio María (2005): "La Corte Suprema como garante de la autonomía municipal”, publicado en la Revista "Debates de Actualidad”, No 195, Asociación Argentina de Derecho Constitucional, pp. 146 y sgts.

HERNÁNDEZ, Antonio María (2007): La parlamentarización de los sistemas presidenciales, Instituto de Investigaciones Jurídicas de la UNAM y el Colegio Nacional de México, México.

HERNÁNDEZ, AnTONio María (2007): "El regreso a la jurisprudencia convalidatoria de la emergencia económica”, Debates de Actualidad, No 198, enero-diciembre de 2007, Asociación Argentina de Derecho Constitucional, págs. 25 y sgts.

HERNÁNDEZ, Antonio María (2008): “Aspectos fiscales y económicos del federalismo argentino”, pp. 11 - ss. En: HERNÁNDEZ, Antonio María, Aspectos fiscales y económicos del federalismo argentino, Instituto de Federalismo de la Academia Nacional de Derecho y Ciencias Sociales de Córdoba, Córdoba.

HERNÁNDEZ, Antonio María (2008): "Las retenciones, el hiperpresidencialismo y las violaciones constitucionales", Debates de Actualidad, No 200, mayo-diciembre de 2008, Asociación Argentina de Derecho Constitucional, pág. 40 y sgts.

HERNÁNDEZ, Antonio María (2009): Balance de la reforma constitucional de 1994, La Ley, Buenos Aires.

HERNÁNDEZ, Antonio María (2009): Federalismo y Constitucionalismo Provincial, Abeledo Perrot, Buenos Aires.

HERNÁNDEZ, Antonio María (2012): Fortalezas y debilidades constitucionales. Una lectura crítica en el Bicentenario, Abeledo Perrot, Buenos Aires.

HERNÁNDEZ, Antonio María (2013): Democratizar no es partidizar, La Voz del Interior, Córdoba, 11 de abril de 2013. 
HERNÁNDEZ, ANTONio María (2014): "20 propuestas para fortalecer el federalismo argentino”, publicado en la página web del Instituto de Federalismo de la Academia Nacional de Derecho y Ciencias Sociales de Córdoba y en el Suplemento de Derecho Constitucional de La Ley, Buenos Aires.

HERNÁNDEZ, Antonio María (2014): El federalismo, ausente en el impulso de YPF, Clarín, Sección Opinión, pág. 25, 8 de julio de 2014.

HERNÁNDEZ, Antonio María, ZOVATTO, Daniel y MORA Y ARAUJO, MANUEL (2005): Encuesta de cultura constitucional: Argentina, una sociedad anómica, editado por la Universidad Nacional Autónoma de México, México.

LINARES QUINTANA, SEgundo V. (1953): Tratado de la ciencia del derecho constitucional, Tomo II, Alfa, Buenos Aires.

NinO, Carlos Santiago (1992): Fundamentos de Derecho Constitucional, Astrea, Buenos Aires.

NinO, Carlos Santiago (1992): Un pais al margen de la ley, Emecé, Buenos Aires, 2a Ed.

QUIROGA LAVIÉ, Humberto (1996): El Poder Constituyente en acción, Editorial Abaco, Buenos Aires.

VALADÉS, DIEGo (2007): La parlamentarización de los sistemas presidenciales, Instituto de Investigaciones Jurídicas de la UNAM y el Colegio Nacional de México, México.

VALADÉS, Diego (2008): El Gobierno de Gabinete, Universidad Autónoma de México, Santa Fe, 2008.

VALADÉS, Diego y CARBONELL, Miguel (2000): Constitucionalismo iberoamericano del siglo XXI, UNAM, México. 